\title{
Successful business models for service centres: an empirical analysis
}

\author{
Paolo Gaiardelli \\ Department of Management, Information and Production Engineering, \\ University of Bergamo, Bergamo, Italy, and \\ Lucrezia Songini \\ Department of Economics and Business Studies, \\ University of Eastern Piedmont Amedeo Avogadro, Novara, Italy
}

\begin{abstract}
Purpose - The purpose of this paper is to analyse the fit between the strategy of service centres and their business model (BM) and to identify the BM components' characteristics and links that allow it to stand out in terms of service delivery and business performance.

Design/methodology/approach - This study applies an inductive qualitative multiple case study approach through the empirical analysis of top-performing Italian service centres operating in the Medium-Heavy Commercial Vehicle sector.

Findings - Research findings underline that the BM components of top performers are consistent amongst each other and with the adopted strategy and make a positive impact on the firm's performance. In particular, top performers are characterised by a solid financial structure based on equity, formalised and flexible organisational structures and processes, clarity in strategic direction and long-term orientation, grounded capabilities, competences and skills, trustful relationships with main service partners and a comprehensive set of managerial mechanisms.

Research limitations/implications - This paper presents some limitations, typical of qualitative research based on case studies. Future works may include other dimensions of performance for identifying top performers, and extend the empirical analysis to different sectors and national contexts.

Originality/value - This paper supports the relevance of contingency theory - particularly the strategy-structure-performance paradigm - in the analysis of the role of a BM in successful servitization strategies of service centres. It highlights that the BMs of the top-performing companies are characterised by some common elements. From a practical perspective, the authors provide insights that can be useful for designing successful service-based BMs for service networks.
\end{abstract}

Keywords Business model, Servitization, Service centres, Top performer, Medium-heavy commercial vehicle industry

Paper type Research paper

\section{Introduction}

The last years of the recent industrial history have been marked by an ever-changing business environment (Dimache and Roches, 2013), characterised by emerging environment-, market-, economy- and technology-related issues (Westkamper et al., 2001). In response to these changes, many industries have evolved their business models (BMs) by shifting from a pure product orientation to integrated product-service systems (PSSs) (Lay et al., 2009). This phenomenon known as the servitization of manufacturing (Baines et al., 2009) - has emerged as necessary to enhance competitiveness of modern manufacturing enterprises (Bikfalvi et al., 2013).

(C) Paolo Gaiardelli and Lucrezia Songini. Published by Emerald Publishing Limited. This article is published under the Creative Commons Attribution (CC BY 4.0) licence. Anyone may reproduce, distribute, translate and create derivative works of this article (for both commercial and non-commercial purposes), subject to full attribution to the original publication and authors. The full terms of this licence may be seen at http://creativecommons.org/licences/by/4.0/legalcode
Business models for service centres 
IJPPM 70,5

1188

Many examples have shown that successful servitization strategies require adaptation of BM configuration and management (Adrodegari and Saccani, 2017) and push companies to go beyond their boundaries to express a business ecosystem (Zott and Amit., 2010). In particular, literature underlines that servitization transformation requires manufacturers to reorganise towards integrated and extended networks (Oliva and Kallenberg, 2003; Chesbrough, 2007) to get the necessary service knowledge, capabilities and capacity demanded by the market (Martinez et al., 2010). This characteristic is confirmed by several industrial cases showing that service delivery generally adopts a service triad logic (Siltaloppi and Vargo, 2017), according to which some external service partners act as suppliers of services in place of the manufacturers to satisfy customer needs. Therefore, service partners' decisions and actions can affect significantly the effectiveness of the service delivery and contribute to the value proposition of manufacturers who are intended to become servitised (Finne and Holmström, 2013).

Among others, a service centre, defined by the Cambridge Dictionary as a "place where a company provides help for customers who use its products or services" is a typical service partner that contributes to enhancing customer loyalty and retention through efficient and effective activities (Saccani et al., 2007). Though they may provide effective services, service centres have been generally neglected by researchers, as these organisations have always been considered as mere executors of manufacturer servitization strategies. Instead, service centres are often independent organisations which, despite being bound by partnership contracts, are characterised by their own decision-making autonomy and distinctive BMs that can considerably influence the service delivery success. Therefore, understanding the dynamics behind BMs of these organisations emerges as an important aspect to explore to understand how manufacturers can transfer their servitization strategies into operational excellence. Indeed, only through running efficient and effective service centres do manufacturers have the opportunity to implement a winning servitization strategy and maintain stable and lasting relationships with their customers.

According to Zott and Amit (2007), the best way to understand the dynamics behind successful BMs is to analyse the behaviour of those companies that have been able to achieve optimal results from a wide point of view, including financial, organisational and strategic performances (Kaplan and Norton, 1992). This statement follows the contingency theory (Chandler, 1962; Child, 1975; Luthans and Stewart, 1977) which argues that a firm can achieve high performance only if it can translate its strategy into a coherent BM.

For these reasons, the objective of this paper is to analyse the fit between service centres' strategies and their BM and to identify the characteristics of BM components and linkages that allow firms to lead in terms of service delivery and overall performance. These research questions (RQs) are pursued: What are the most relevant BM components consistent with the peculiarities of service centres? How do BM characteristics fit with firm strategy? How should $\mathrm{BM}$ components be characterised and interconnected with each other to achieve a high level of firm performance?

By responding to these RQs, we aim to fill a gap in the academic knowledge by theorising the components of service-based BM, their characteristics and relations, and their consistency with firm strategy and their role in firm performance. In particular, the perspective of service centres is considered to provide practical insights for designing successful service-based BMs for manufacturing firms and service centres.

To address the research aims and questions, this study applies an inductive qualitative multiple case study approach (Yin, 2009), through the empirical analysis of 19 top-performing Italian service centres operating in the Medium-Heavy Commercial Vehicle (MHCV) sector. The choice to study only one industrial sector is consistent with Zott and Amit (2008, p. 20) who highlighted the need to "investigate competition among various business models within an industry." The MHCV sector - i.e. any companies producing and/or distributing goods and services for trucks with a gross combination mass of over 3.5 tonnes (www.acea.be) - has 
been selected because of the high contribution of services to the strategic, competitive and financial results. This sector is configured as several complex and fragmented service networks (Gaiardelli et al., 2007) where both manufacturers and their service centres, the so-called official service channel, have to develop new forms of services and new operational capabilities to maintain their competitive position.

This paper is structured as follows. First, we review relevant literature on strategy, BM definition and characteristics and their relationships. Next, we introduce the research methodology. After that, we present the findings emerging from the analysis and discuss their implications. Finally, we present the conclusions along with the identification of limitations and possible further developments of the study.

\section{Literature review}

The literature review is structured in three main parts. The first presents the main studies on the relationships between strategy, BM and performance. Then, the most relevant components of BM found in the literature are discussed. Finally, the main studies on service-based BM are outlined.

\subsection{The relationships between strategy, business model and performance}

A company's strategy consists of a set of decisions and actions aimed at a defined goal. Aiming at lasting success, the strategy has as its goal what to produce, for whom, how and with what logic. Many definitions of strategy have been proposed in the management literature (Chandler, 1962; Porter, 1980). Mintzberg (1994) recognises that strategy may have several meanings and proposes five definitions. He also provides a distinction between intended and realised strategies, and he emphasises the importance of emergent strategy as an alternative or complement to deliberate strategy. If a deliberate strategy is defined by management, an emergent strategy consists of patterns that realise despite - or in the absence of - intentions. Emergent strategy arises informally at any level in the organisation. Since the 1970s, the literature has analysed the relationship between strategy, structure and firm performance. According to the contingency theory (Galbraith, 1977; Miles and Snow, 1978) the fit, or coherence, between contingency factors such as strategy and structure, represents the main determinant of higher performance. In line with the research approach adopted by Nadler and Tushman (1997) and Yin and Zajac (2004), a BM can be viewed as "a structural template of how a focal firm transacts with customers, partners, and vendors" (Zott and Amit, 2008, p. 1). It identifies a "conceptual framework containing a set of objects and concepts together with their relations with the goal, aimed to express the underlying logic of business" (Osterwalder et al., 2005 , p. 3), thus representing the "design or architecture of the value creation, delivery and capture mechanisms" (Teece, 2010, p. 172). Some authors propose that BMs are sources of competitive advantage as they allow effective strategy change (Magretta, 2002).

Definitions of BM available in the literature can be generalised into three main views: (1) A BM is an overarching concept that can describe all real-world business; (2) it addresses a set of businesses with common characteristics and (3) it describes different aspects - or conceptualisations - of a particular real-world business (Orellano et al., 2017). Although researchers have expressed different views about the notion, structure and evolution of BMs, all such contributions have converged on the fact that a BM explains how a business creates and delivers value to customers (Al-Debei and Avison, 2010). Thus, we may propose that a $\mathrm{BM}$ is substantial to any organisation as it provides a concrete avenue to understand, analyse, communicate and manage strategic, operational and economic decisions (Osterwalder et al., 2005; Shafer et al., 2005).

The majority of scholars argue that BM and strategy are distinct concepts even though they are linked. According to Zott and Amit (2008), BM and product market strategy 
IJPPM 70,5

1190

complement each other and are not substitutes as the first can be conceived as an abstraction of the second (Seddon et al., 2004). Casadesus-Masanell and Ricart (2010) suggest that a BM results directly from strategy but it is not a strategy itself. Magretta (2002, p. 94) highlights that "... a business model isn't the same thing as strategy [. . . . Business models describe, as a system, how the pieces of a business fit together. But they do not factor in one critical dimension of performance: competition. [...] Dealing with that reality is strategy's job."

Most authors see a role for the BM in implementing the strategy. Adopting the contingent strategy-structure-performance perspective, these authors consider the BM as an indispensable structure aspect of strategy execution success (Kaplan and Norton, 2000), as it is used to design or check on how the firm is executing its strategy and doing business (Richardson, 2005). Finally, "business models are reflections of the realized strategy" (Casadesus-Masanell and Ricart, 2010, p. 204).

\subsection{The main components of a business model}

Existing studies about BMs generally provide a narrow perspective on a few specific BM components, while studies with a comprehensive vision are still a minority (Wirtz et al., 2016). However, summarising the different contributions of literature, it can be stated that a BM is composed of more than 54 different elements (Abd Aziz et al., 2008). According to Shafer et al. (2005), these elements can be categorised into four major categories: strategic choices, creating value, capturing value and the value network. An analysis of proposals from Morris et al. (2006), however, identify six key decision areas at the heart of every BM: factors related to offering (How do we create value?), market factors (Who do we create value for?), internal capability factors (What is our source of competence/advantage?), competitive strategy factors (How do we differentiate ourselves?), economic factors (How we can make money?) and personal/investor factors (What are our time, scope and size ambitions?).

A recent study carried out to prioritise the components of a BM suggested that value proposition, customers, internal competencies and revenue models are considered the most common elements included in a BM framework (Adrodegari and Saccani, 2017). A value proposition is a central element fuelled by key partners, key activities and resources to solve the customer segment through appropriate relationship and channels. These activities are supported by cost structure to generate revenues (Orellano et al., 2017). Nevertheless, the variety of BM elements show that different structures can be used to create a BM (Barquet et al., 2013).

\subsection{Service-based business models}

Different research communities have highlighted the need to investigate how to integrate the viewpoint of service into a BM to assist service adoption in the context of PSSs (Richter et al., 2010). In this context, a service-based BM can be seen as a tool that managers can use "to visualise changes which should increase internal transparency, understanding and awareness of service opportunities and necessary changes" (Kindström and Kowalkowski, 2014, p. 96). Within the PSS literature, BMs are frequently mentioned or discussed. According to Reim et al. (2015), although 67 articles explicitly or implicitly address PSS BMs, these models receive little attention from researchers (Boons and Lüdeke-Freund, 2013).

The adoption of a canvas structure and its nine components proposed by Osterwalder and Pigneur (2010) has been identified in the literature as the most suitable approach to guarantee a comprehensive characterisation of service-based BMs (Adrodegari et al., 2017; Orellano et al., 2017; Barquet et al., 2013). Some studies provide different service-based BM frameworks with generic and relevant elements regarding both product-centric firms and pure service players (Storbacka et al., 2013; Kindström, 2010; Nenonen and Storbacka, 2010). In addition, some authors believe that a PSS is a BM that supports servitization and comprises the four traditional components of a BM, i.e. offering, market 
segment, value chain and finance (Fitzroy and Hulbert, 2005; Kaplan and Warren, 2009), plus two additional elements. These elements are the business strategy as the driving force for all the other elements along with sustainability as an important measure of the business' success (Dimache and Roche, 2013).

Recently, Adrodegari and Saccani (2017) proposed a BM reference framework for servitised firms, which is comprised of typical BM components: strategy, finances, value proposition, revenue model, resources, service provision, customer and network. However, it is worth noting that literature on service-based BMs generally focusses on the manufacturers, while the analysis of BM adopted by service centres has been mostly neglected.

\section{Research methodology}

Considering the interplay between theory and empirical phenomena (Dubois and Gibbert, 2010), this paper follows an inductive approach, looking at specific cases to underpin further development in BM from the perspective of service centres. Due to the early stage of research on the topic, we applied an inductive qualitative multiple case study approach (Yin, 2009). A case study methodology is appropriate when little is known about a phenomenon as it allows the researcher to go deeper into an issue and to gain knowledge based on evidence surfacing through the cases (Yin, 2009; Eisenhardt, 1989).

An empirical analysis was carried out of the 19 best Italian service centres operating in the MHCV sector. This sector was selected to partially isolate the effects of the strategic context from other potentially confounding factors. As argued by others (Rishi et al., 2009), there are several current and historical examples of service solutions in the MHCV sector, making it an appropriate and interesting empirical field to investigate. Services may constitute an answer to the complex forces shaping this industry (Porter, 2008). In addition, the high contribution of services to the strategic, competitive and financial results of the $\mathrm{MHCV}$ industry has boosted the development and diffusion of new players in this arena (Gaiardelli et al., 2007). In this context, manufacturers and their service centres have been forced to develop new services and operational capabilities, favouring a radical change of their strategic, organisational and managerial approaches (Gaiardelli et al., 2014).

This analysis was carried out in the Italian context due to the relevance of the MHCV industry and the features of the service network. Furthermore, Italy has many service centres throughout the country (Gaiardelli and Songini, 2018). This market has undergone a period of deep crisis from 2008 to 2014, progressively reducing the service activities. This affected all major medium-heavy truck brands and had negative consequences on the revenues and margins of the service network. But data on the industry macro-dynamics pointed out that, contrary to the general trend, a few service centres that grasped the opportunities offered by the crisis consolidated their lead and achieved successful performances (Gaiardelli and Songini, 2018). Thus, it could be interesting to understand the characteristics of service-based BMs of such high performing service centres. We analysed in depth some cases of service centres which can be considered top performers.

The selection of case studies was done based on the results of preliminary meetings held with top senior service managers of the seven most relevant companies operating in the Italian MHCV market. To identify the criteria for top performer selection, a wide definition of performance was adopted. As suggested by studies on performance (Lynch and Cross, 1991; Fitzgerald et al., 1991; Kaplan and Norton, 1992), the selection criteria would include financial data, market and customer data, as well as process and innovation. Then, according to a shared definition of performance, a list of key performance indicators (KPIs) was identified around competitive position (market share), financial performance (profitability), customer satisfaction and process efficiency. The same KPIs were selected and measured for all service centres belonging to the seven brands to allow consistent comparison of data. The four best service 
IJPPM 70,5

centres for each of the seven manufacturers were identified (i.e. 28 workshops). The selection was based on the following: (1) first, the service centres were ranked according to the results achieved in each performance area, (2) rankings were weighted, using a 5:3:1 approach with the best centre receiving five points, the second three points and the third one point, (3) an overall score was calculated summing up the evaluations achieved in each performance area and (4) for each brand, the four service centres characterised by the highest overall score were considered.

The 28 workshops constituting the initial sample were contacted and asked to join the research, and 19 companies agreed to be interviewed. All of them were SMEs operating throughout Italy: 14 were located in the north, three in the centre and two in the south. Under the methodological approach adopted by Lockamy (1998), two documents were used to obtain consistent and complete information from the interviews while avoiding the respondent being influenced by the questions. The first document - covering general information about the topics to be covered in the interview - was delivered one week before the meeting to help the interviewee prepare. The second document - containing the questions in detail - was used by the interviewers to conduct their interview. Then, face-to-face interviews were conducted by three researchers. These lasted between one to three hours. Twenty-nine people were interviewed: $10 \mathrm{CEOs,} \mathrm{five} \mathrm{managing} \mathrm{directors,} \mathrm{five} \mathrm{after-sales}$ service managers, five sales managers and four administrative managers. Of these, 17 were company owners or members of the family who owned the business. The interviews included semi-structured and open-ended questions, allowing interviewees to talk freely about their company. This way, additional relevant factors would emerge.

Questions were designed to explore the two following aspects: (1) general questions on the characteristics and strategy of the firm and (2) questions to analyse the service-based BM components, their features and links. The latter included general questions in terms of processes and networks, organisation, product and service portfolio configuration, customer relationship management and performance measurement and control. This part of the interview provided as a substantial amount of qualitative data.

All interviews were recorded. Next, the conversations were transcribed, and the responses were grouped into themes and sub-themes to generate a thematic map, which was used to develop a coding frame. Each of the three researchers independently performed the coding, and the results were then compared. We used a process from Voss et al. (2016), who suggested a three-step coding method adopted from the one originally proposed by Strauss and Corbin (1990). This process included regrouping and linking categories in a rational manner allowing a chain of evidence.

Following Pettigrew's approach (1990), a within-case analysis was then carried out to be familiar with each top performer's strategy and BM. Each case was summarised in a table and a relationship map was developed specifying the main characteristics of each BM component and its relationship with the adopted strategy and other BM elements. Subsequently, the within-case analysis was combined with a cross-sectional study to build a pattern of similarities between cases, which was then summarised in a general relationship map. Although there are dissimilarities amongst cases, the strong congruence of BM components and the adopted strategy highlighted by cross-sectional analysis allows for the generalisability of the proposed model underlying a low level of dependency on individual companies' characteristics.

\section{Research findings and discussion}

In this section, we present the main findings of the case study analysis, which highlights the top performers' strategy BMs commonalities and relationships. The first part of the empirical analysis describes the main characteristics of the analysed companies. The second part presents the distinct traits of service centres' strategy and BM configuration. The last part 
introduces a discussion on the link between strategy and BM and the mutual relationship amongst BM components.

\subsection{Main characteristics of service centres}

According to the industry trend, all the interviewed companies are SMEs. In particular, $32 \%$ of the sample consists of medium-sized companies, $52 \%$ of small-sized and $16 \%$ of micro-sized companies operating throughout Italy. Of the 19 interviewed, 17 firms were family-owned businesses. Table 1 shows the companies participating in this research with their geographical position, size and reference brand.

\subsection{Strategy and business model characteristics}

Overall, research findings highlight that top performers' BMs are characterised by some commonalities in their servitization strategies and BM. These can be grouped into eight main components: value proposition, customer, network, service provision, finances, organisation, revenue model and resources and capabilities. The number and the identified BM components follow Adrodegari and Saccani (2017), except for the concept of strategy, which we considered a determinant of BM in the strategy-structure-performance paradigm (Galbraith, 1977). We also added resources - which our research findings highlighted as strictly integrated with capabilities - and organisation, which emerged as an additional component. Common elements of top performers' BMs are summarised and briefly described in Table 2.

In the data that follow, statements from the interviews are listed in support of the findings.

4.2.1 Strategy. Strategy formulation derives from a mix of deliberate and emergent strategies. Deliberate strategy is mostly defined and guided by the manufacturer focal firm, while emergent strategy arises informally and stems from the owner's entrepreneurship. Growth and differentiation strategies are noted as the two main strategies driving firm performance. Growing both internally and externally as well as diversifying the offer allow top performers to create and maintain competitive advantages as well as to generate high financial performance.

\begin{tabular}{llll}
\hline Company & Location & Size & Brand \\
\hline Company 1 & North-west & Medium & IVECO \\
Company 2 & North-west & Medium & IVECO \\
Company 3 & Centre & Medium & DAF trucks \\
Company 4 & North-east & Small & Volvo trucks \\
Company 5 & North-east & Small & Volvo trucks \\
Company 6 & Centre & Micro & Renault trucks \\
Company 7 & North-east & Medium & MAN truck and bus \\
Company 8 & North-west & Small & Volvo trucks \\
Company 9 & North-west & Small & DAF trucks \\
Company 10 & North-west & Small & DAF trucks \\
Company 11 & North-west & Micro & Renault trucks \\
Company 12 & North-west & Medium & IVECO \\
Company 13 & South & Small & DAF trucks \\
Company 14 & South & Small & Volvo trucks \\
Company 15 & Centre & Medium & Mercedes-Benz \\
Company 16 & North-east & Micro & MAN truck and bus \\
Company 17 & North-west & Small & MAN truck and bus \\
Company 18 & North-west & Small & Scania \\
Company 19 & North-east & Small & Scania
\end{tabular}

Business models for service centres

1193

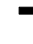




\section{IJPPM} 70,5

\section{4}

Top performer characteristics

Strategy

(1) Growth: internal, external and through diversification

(2) Deliberate and emergent

Components of a BM

Value proposition

(1) Extension of service offerings towards product-focussed services, customer-focussed services and business-focussed services

(2) Value generation in other ways such as personalisation, ongoing service and integrated offers (bundling)

Customer

(1) Adoption of multiperspective approaches for customer profiling and segmentation

(2) Improving customer relationship through long-term agreements, mutual trust and transparency

(3) Involving the customer in service delivery

(4) Rethinking new sales channel via smart technologies (e-commerce), proactive promotion and communication aligned with customer types

(5) Following the integrated commercial policies especially between sales and after-sales

Network

(1) Establishing a relationship based on mutual trust with other network players and internal synergy and collaboration

(2) Adoption of centralising coordination

(3) Extending highly collaborative networks even with competitors to support a co-opetition perspective

Service provision

(1) Increasing the process efficiency through task flexibility, method standardisation and simplification of operative activities. This also allows for an increase in customer satisfaction

(2) Adoption of lean manufacturing principles to reduce the average waiting time and also stimulate demand for services

Finances

(3) Saturating the installed capacity as a key point to gain efficiency

(1) Capitalisation and long-term investment planning as a consequence of a solid financial structure

(2) Family shareholders are willing to reinvest profits in the company growth

Organisation

(1) Structuring a flat, lean and centralised organisation encompasses the internal coordination and synergy with the development of cross-functional working groups empowered on common goals

(2) Clarifying the roles and relative responsibilities and decentralising front-office activities

(3) Adoption of different incentive schemes such as informal systems dedicated to groups or individuals, and formal employee assessment system

(4) Monitoring the business performance constantly and applying an integrated system for measurements with multiple perspectives

(5) Both entrepreneurship and managerialisation are leveraged

Revenue model (1) Pricing strategy is generally value-based, and it evolves from the value perceived by customers

(2) Developing customised pricing policies based on different customer needs and types

(1) Applying sophisticated Information and Communication Technologies (ICT) and monitoring technologies with other managerial tools

Table 2.

Resources and capabilities

(2) Developing recruitment systems to identify the right resources for the right role with propounding the competences around soft and rational skills

(3) Focus on human capital: competences, capabilities and skills

Consolidating is not sufficient anymore. Today, we have to pursue progress through growth ... (Company 14).

Differentiation in terms of services proved to be a winning strategy ... (Company 15). 
Internal and external growth is pursued by top performers. Internal growth implies the use of existing resources and organisation and leverages economies of scope that are achieved through developing complementary businesses or new services based on current capabilities and the exploitation of existing service capacity.

You need to work on complementary businesses and new services using the installed capacity and available resources (Company 3).

External growth is obtained through mergers with partners or acquisition of external actors that allow territorial and business expansion, and through strengthening a network of alliances.

Our group owes its success both to the territorial expansion and to the internal change pursued over years (Company 18).

We are trying to invest in the most profitable workshops to control the market (Company 2).

The network has been fundamental for the growth of our business ... We rely on insurance and leasing companies, on tyre specialists and spare parts retailers (Company 1).

Moreover, according to the essence of the MHCV market, which is highly mature and characterised by fragmented demand and diversified customers' needs, all the top performers have adopted differentiation strategies. These companies have exploited the potential opportunities for differentiation in their business enlarging the width of their service portfolio, which comprises not only traditional product-oriented services, such as maintenance and repair but also user-oriented solutions, such as leasing and renting. Other sources of differentiation include the type of served vehicle (car, bus and commercial vehicle), served customer (fleet company, public transportation, logistic operator or single-truck owner) and territorial area.

We decided not to focus solely on the medium-heavy truck market, but also light commercial vehicles, buses and cars (Company 6).

Territorial distribution is an element that diversifies us and helps us fight the competition (Company 15).

Top performers also differentiate their offerings via multibrand and in selling optional components, merchandise and spare parts aimed at a highly profitable niche market.

Differentiation strategies are also addressed to complementary or even new businesses. In particular, other sectors which require similar technical skills and equipment of automotive industry - like naval engines or cogeneration plants industries - are considered as the market with the most potential to enter. Indeed, by exploiting resources and expertise that already exist in the company, it is possible to increase the critical mass and to saturate the production capacity, especially when the reduced demand for traditional activities does not make good use of available resources.

Diversification on parallel businesses can be considered a further chance to deal with the crisis (Company 19).

4.2.2 Value proposition. Top performers enhance the value for customers by adopting two perspectives: the provision of a service portfolio based on a wide range of standard services offered to all customers, on the one hand, and integrated and bundled solutions of products and services customised and tailored according to the specific needs of specific customers, on the other hand.

With the economic crisis involving a dramatic reduction in product sales volumes and the working fleet, it has become almost inevitable to look for new business opportunities in 
IJPPM

70,5

1196

services. Thus, service portfolios have been diversified including new solutions to support product functionalities, drivers' activities and business management. Moreover, comprehensive service solutions, tailored according to the vehicle characteristics, customers' needs and designed to build long-time relationships have emerged as winning solutions. In this way, top performers have fulfilled the one-stop solution and shop-in-shop approach. The first service concerns the possibility of intervening in the tractor and auxiliary components of the MHCV in a single operation to reduce vehicle downtime. The second refers to the possibility of working directly on the vehicle at the customer's premises, thus avoiding transfer times to and from the workshop.

The secret is to offer a complete service in one act to reduce the vehicle downtime [...] tailored solutions according to the vehicle characteristics and the needs of our customers (Company 7).

4.2.3 Customer. Entering into long-term contracts with customers allows top performers to increase customer involvement and interaction during service delivery and in the product and service life cycle. Commercial activities are conducted with the utmost respect for the customer and his business objectives. Service sales are managed together with the customer, who is involved since negotiation.

[...] sharing with the customer resources and information in terms of sales and after-sales (Company 1).

Furthermore, transparency in all service delivery allows to establish win-win relationships with customers:

Only by establishing mutual trust relationships based on the transparency of both the service provider and the customer we can both get winning results! (Company 9).

Many actions are implemented in daily activities to increase customer loyalty and establish transparent relationships. For example, top performers adopt technological arrangements that make work processes more visible and controllable. For instance, the use of cameras inside the workshop allows the customer to have an overview of the workshop and the activities that take place. For the same reason, the acceptance processes were redesigned to avoid an incorrect estimate. To foster a win-win approach, the customer is required to severely respect contract terms and conditions (such as payment deadlines). Otherwise, the name of the transgressor will be communicated to the entire network and excluded from all those promotions and exclusive commercial advantages dedicated to virtuous and trusted customers. On the other hand, the service provider has to be transparent and respectful in terms of deadlines and prices negotiated with the customer.

Moreover, customer segmentation is important to achieve an effective value generation (Nenonen and Storbacka, 2010). One of the key success factors is connecting the appropriate value proposition with the right customers (Kindström, 2010). For this reason, top performers profile customers dynamically from a multiperspective such as solvency, financial statements and geographical position.

Among the different market analyses, we leverage also on geo-marketing, which is very important for understanding both manned and unmanned areas (Company 15).

Top performers also implement proactive communication and promotion policies tailored for the selected targets, while sales channels are aligned with commercial policies.

The channels used to promote promotional campaigns depend on the target they are targeted to (Company 6).

We have created custom postcards to inform customers of various promotions (Company 9). 
Several communication channels are applied to reach different categories of customers simultaneously underpinning the feedbacks of each to ameliorate their marketing and communication strategies. This study depicts a shift from traditional distribution to e-commerce due to the advent of smart technologies.

We use information coming from the channels to improve the next promotional campaigns (Company 13).

We are launching a business application for the sale of spares via smartphones (Company 8).

4.2.4 Network. Developing network and partnership infrastructure based on mutual trust agreements as well as internal synergies and collaborations with the other network players are key elements of success.

We have formal agreements with our partners and suppliers based on mutual trust. In such agreements, our partners must guarantee quality standards at fixed prices for different types of service (Company 1 ).

The best-performing companies not only establish formal agreements with their partners but also adopt centralising coordination through their networking structure to achieve processes efficiency.

We had to merge some facilities and share some activities with our partners to ensure a more sustainable business (Company 17).

Sometimes, even competitors are involved from a co-opetition perspective, exploiting their excellence in specific areas and delegating more operational tasks to focus on a more strategic and coordination role. Therefore, highly collaborative extended networks emerged, where technical skills are important and organisational and strategic capabilities are fundamental.

Collaboration with the other workshops and, if necessary, with the leaner competitors are essential to ensure the best service for our customers (Company 9).

Sophisticated ICT and monitoring technologies are applied with other managerial tools for integrated control of the whole network. Moreover, top performers implement formal systems for planning and control performances of both the downstream and upstream service chains.

We are integrated with the operating system of some partners to facilitate our planning and the integrate control of the process (Company 5).

4.2.5 Service provision. Task flexibility and method standardisation are two key elements for increasing process efficiency.

...we are flexible in our tasks but structured in the method used. [. . .] the method can be discussed, but once it has been approved by all, it should be recognised as a standard (Company 18).

Through long- and short-term decisions, top performers aim at increasing and saturating the production capacity as well as simplifying their operative activities. Indeed, as stated by Davies et al. (2007), formalising, specifying and standardising services are critical for taking advantage of economies of repetition to deliver services at a lower cost and more effectively (Kindström and Kowalkowski, 2014).

Under these conditions, top performers have tried to implement approaches aimed at improving the use of production capacity. On the one hand, for example, they have intervened by improving vehicle management processes (from acceptance to delivery) through the adoption of lean manufacturing principles. Planning has been simplified and the acceptance has been improved:

We need to aim for proactive customer acceptance to reduce downtime (Company 5).
Business models for service centres 
IJPPM

70,5

The process of sourcing spare parts has been optimised, while the service activities have been standardised:

We have mapped our processes to find the optimal solution for vehicle repair (Company 5).

Moreover, the monitoring of all operating activities has made mandatory:

... the control of time with barcodes has allowed us to improve control and facilitate operational improvement (Company 3).

The reduction in the average waiting time not only allows efficiency improvements but it also stimulates demand for services and customer satisfaction.

4.2.6 Finances. Capitalisation and long-term investments are fundamental to reduce vulnerability to future recession (Kindström and Kowalkowski, 2014), as these can improve both efficiency and effectiveness of existing activities and increase revenues and profits through the development and launch of new products and services. In an industry where firms' debt-to-equity ratio is generally high (Gaiardelli and Songini, 2018), top performers' financial structure, on the contrary, mainly leverages on equity. Indeed, top performers grow in terms of investments and revenues thanks to a solid financial structure. A solid financial position, indeed, emerges as crucial, since it grants the necessary resources to implement manoeuvres that increase the efficiency and the effectiveness of existing activities. Moreover, a solid financial position enables companies to invest in service and product innovation as well as strengthen the existing organisational structure. In particular, growth occurs maintaining the level of debt constant and restrained, thanks to an adequate supply of equity, mainly through reinvested profits. In fact, shareholders, usually belonging to the same family, are more interested in the long-term survival and growth of the family business than in yearly dividends.

The market is mature, and no new entrepreneurs enter the industry. Only companies who have been consolidated over time and have a stable capital and financial structure can resist (Company 12).

4.2.7 Organisation. The research highlights the importance of having clearly defined roles and responsibilities within the organisation as well as shared goals supported by management systems and appropriate incentive policies to implement efficient and effective decisions.

Each one has its role within the organisation [...] roles, tasks and responsibilities are well defined (Company 2).

Objectives are formalised to involve all employees and create a sense of group identity (Company 7).

The organisation structure is lean, flat and centralised. This leads to a fast decision-making process and few unproductive units. Moreover, internal coordination and synergy within different sections and departments enable information sharing and create the condition for the development of cross-functional working groups empowered on common goals. This type of organisation creates favourable conditions for higher efficiency and better customer relationship.

We have tried to create the conditions to generate a strong interaction between sales and after-sales that is necessary to have an overall view of the customer's needs (Company 1).

Although there are vendors and mechanics dedicated to the type of vehicle, let's make sure that all the figures are interchangeable (Company 12).

Coordination activities are centralised, while those in direct contact with the interface with customers requires decentralisation.

We lose efficiency, but we gain more effectiveness (Company 10). 
In best-performing companies, indeed, employees are involved with different methods to encourage the right motivation. Incentives may be different. In some situations, top performers adopt informal systems dedicated to groups or individuals:

There is no formal incentive policy on the individual, as the owner provides incentives ad personam (Company 10).

In other cases, however, it is used a formal employee assessment system:

Our mechanics are divided into homogeneous teams and the after-sales manager defines different criteria by which teams are evaluated (Company 8).

Moreover, top performers implement formal systems for planning and control their internal results and to monitor the performances of the service network. They not only draft a business plan or an annual budget but periodically draw up various types of analysis and accurate forecasts considering multiperspective measurement:

[...] including budget analysis, monitoring of economic and financial ratios as well as several different KPIs that are easy to control and communicate (Company 7).

A fundamental element of competitiveness is the development of an integrated system for measuring business performances. In particular, the main areas of analysis and assessment concern revenues and gross sales, customer satisfaction and loyalty, production capacity saturation, operational efficiency, service quality level, internal and response time, innovation and human resources skills. In addition, results are systematically measured on several levels, from strategic to operational, and are constantly monitored monthly, weekly and sometimes even every day. Specific indicators are applied to assist constant performance monitoring for each area while business performances are shared with all the players.

It is essential to monitor company performances. We measure them at least weekly (Company 19).

4.2.8 Revenue model. Revenue streams are strongly linked to the perceived value by customers, and the mechanisms to establish the price are generally value-based and not cost-based. Top performers can exploit information taken from the appropriate market analysis - carried out on the basis of different drivers, related to the characteristics of the customers, business and geographical location - and then develop customised pricing policies according to the different components of value for customers and also customer willingness to pay.

We use different channels to profile different customers categories [. . . ] prices are different according to the type of customer served (Company 11).

We adopt different discount rates depending on the level of loyalty of our customers (Company 16).

On these premises, we can affirm that top performers understand how different categories of customers perceive each component of customer value. Consistently, they are able to define personalised pricing policies based on customer value elements.

4.2.9 Resources and capabilities. To ensure integrated and quality solutions, sophisticated ICT and monitoring technologies along with other managerial tools are applied for internal coordination and the integrated control of the whole network. To guarantee consistent performance monitoring, integrated IT devices are adopted.

It is important to have sophisticated computer systems, software for business analysis and customer relationship management for customer profiling and product configuration. (Company 5).

Human resources play a key role in the success of the business. For this reason, top performers develop recruitment systems aimed at identifying the right resources for the right 
IJPPM

70,5

\section{0}

role and focus on personnel with strong soft and relational skills. Nevertheless, continuous training has always been one of the reasons for the company's success, which is indispensable for offering quality service.

We mainly look for people with relational and management skills. Technical competencies developed while working (Company 4).

The constant personnel training has always been one of the reasons for our success. It is essential to offer quality services (Company 7).

Increasing competencies on both customer orientation and after-sales services, through effective training courses, allows a company to offer new services.

First, it is necessary to strengthen the internal structures of the company [...] by developing new competencies and knowledge. Then new services can be developed and offered (Company 14).

\subsection{Discussion}

On the one hand, the empirical analysis allows us to highlight the main characteristics of strategy and each BM component, while on the other hand, it evidences that BM components are connected. Figure 1 provides an overall summary of all connections between strategy and $\mathrm{BM}$ and amongst BM components. Relationships of each component with the others are presented, together with a discussion on to what extent each relationship is influenced by distinctive characteristics of the industrial sector under observation.

4.3.1 Strategy. Our findings show that top performers pursue differentiation and growth strategies as a way to develop a strong and distinctive competitive advantage. The latter is mainly based on a wide, customised and integrated value proposition in terms of service solutions. Moreover, the results suggest that competitive advantage is also related to highefficient operations and saturation of installed capacity. Therefore, we can affirm that successful BMs imply a joint adoption of cost leadership and differentiation strategies, consistent with the so-called confrontation strategy proposed by Cooper (1995). The adopted strategic choice emerges as the best amongst those that can be implemented, as also

Figure 1.

The main relationships between strategy and the BM components of top performers

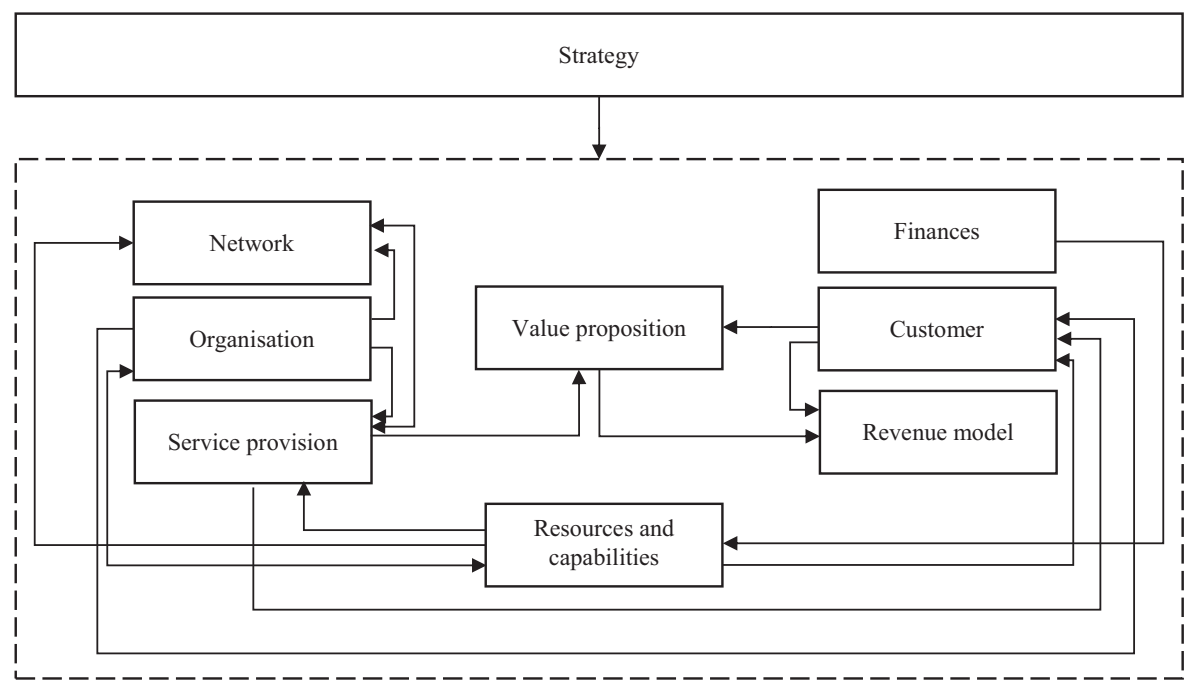


suggested by Adler (2011) who underlined how in highly complex market contexts, such as $\mathrm{MHCV}$, competitive advantage can be pursued only by developing mixed strategies.

Moreover, we observed that to sustain their competitive advantage, top performers reinvested their profits to develop and attract strategic resources (human and technological resources) through the use of appropriate managerial mechanisms. Finally, from the analysis, it emerged that top performers adopt both emergent strategies, driven mostly by the focal manufacturer and deliberate strategies, which stem from the owner's entrepreneurship.

4.3.2 Value proposition. The increase of critical mass of business emerges as essential to prosper in a mature market characterised by fragmented and customised demand. In this context, top performers propose an innovative value proposition based on the provision of customised, integrated and bundled solutions of products and services. This choice makes it possible to attract customers with very different characteristics, ranging from large fleets carrying out integrated logistics services to small companies with a single vehicle where the owner is very often also the driver. Therefore, customer segmentation and profiling emerge as prerequisites for developing a value proposition that can meet customers' needs. In addition, the direct involvement of the customer in the service delivery process throughout the product and service lifecycle, thanks to long-term contracts, enables a better understanding of customer needs, thus allowing the design of tailored service solutions built upon value-based pricing policies. The relationships between the value proposition and other BM components are summarised in Figure 2.

4.3.3 Customer. Customer perception has been changed, which instead of being focussed on the product itself, it is more focussed on the service experience and human values, as commitment and trust (Vargo and Lusch, 2008). Thus, successful companies have to maintain a customer-oriented mindset and increase customer relationships as their priority (Adrodegari et al., 2017). Given the characteristics of their customers - logistics and transport operators primarily interested in the timeliness and reliability of the service - top performers use a wide range of advanced managerial mechanisms and marketing mix solutions to increase customer loyalty and establish long-term win-win relationships (Verstrepen et al., 1999).

A mix of sales, marketing and communication tools along with planning and control mechanisms help in profiling and segmenting customers' needs, creating transparent and long-term relationship, generating customer involvement in service delivery as well as setting the conditions for value-based pricing schemes development. In particular, top performers

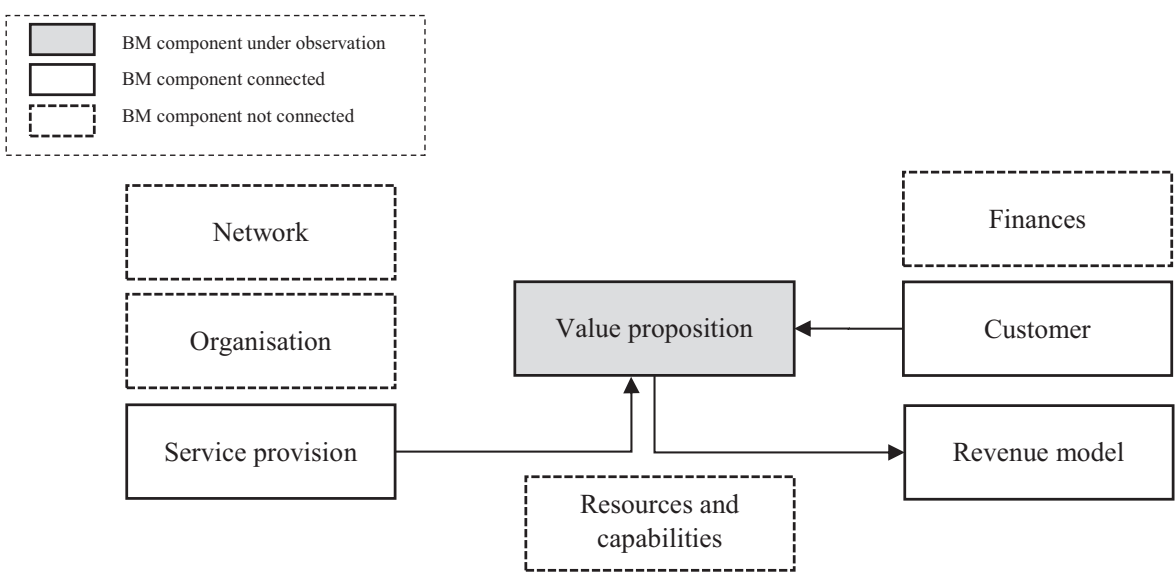

Business models for service centres

1201
Figure 2. The relationships between the value proposition and the other BM components of top performers 
IJPPM 70,5

1202

have been able to take advantage of integrating the use of managerial tools and techniques provided by focal firms to support their partners with direct feedback from their customers during service interventions. The adoption of lean processes and a flat and streamlined organisation - along with the use of appropriate ICT resources - promote transparent relationship management and the integration between the different functions involved and between the customer and the front-line employees. Figure 3 highlights the relationship between the customer and other BM components.

4.3.4 Network. Together with the manufacturer's network, our research findings show that top performers develop and manage their own extensive and independent collaborative networks to achieve long-term partnerships. This approach is the natural consequence of the offer expansion that top performers have undertaken to capture different business needs of their customers. However, the absence of necessary skills rather than inadequate economies of scale necessary to justify investment in new resources has stimulated top performers to create collaborative models. This has allowed them to leverage their technical excellence, delegate operational tasks to partners while taking on a more strategic and coordinating role in the service delivery process. In particular, centralised strategic coordination in a co-opetitive context - developed on formal agreements and supported by network performance monitoring and sophisticated ICT systems - allow for the generation of mutual trust and the exploitation of synergies amongst partners (Windhal and Lakemond, 2006). Adequate technological and human resources ensure the effective and efficient operation of the network. Figure 4 summarises the main linkages that the network BM component has with the other BM elements.

4.3.5 Service provision. In addition to the joint adoption of cost leadership and differentiation strategies, top performers pay close attention to the efficiency of activities and processes, not only to reduce lead times, waste and costs but also to improve effectiveness and customer satisfaction through their involvement in service delivery. Lean management techniques and tools are the most diffused approaches adopted to improve efficiency and effectiveness. This implies clear and formal roles and responsibilities together with a flat organisation, based on cross-functional working groups (Liker, 2004) and trained and skilled personnel. From this point of view, companies have enjoyed the experience of their sector, as the automotive industry is one where the principles of lean thinking were first introduced. Planning and control mechanisms are needed, though, to ensure the efficiency of service delivery processes. In some cases, competitors and/or other network players can be involved

Figure 3.

The relationships between the customer and the other BM components of top performers
BM component under observation

BM component connected

BM component not connected

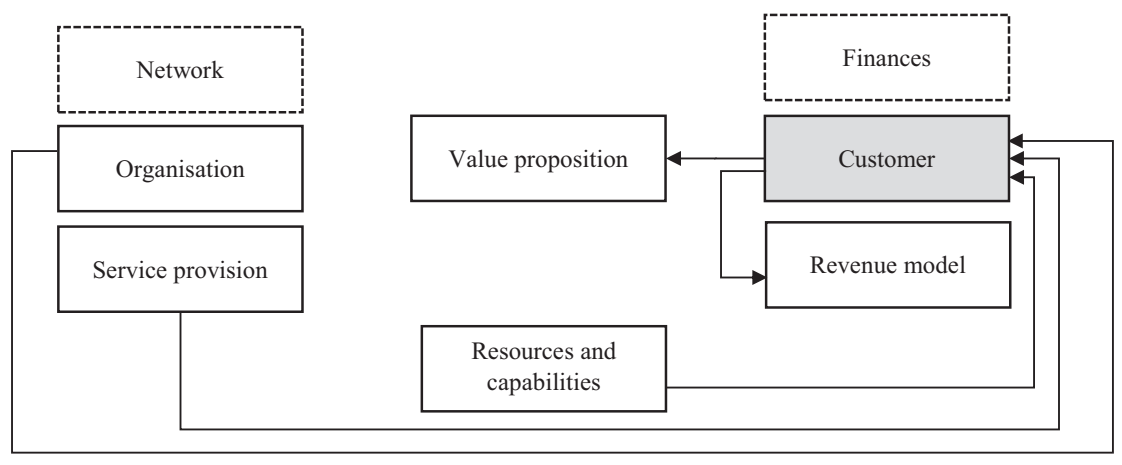



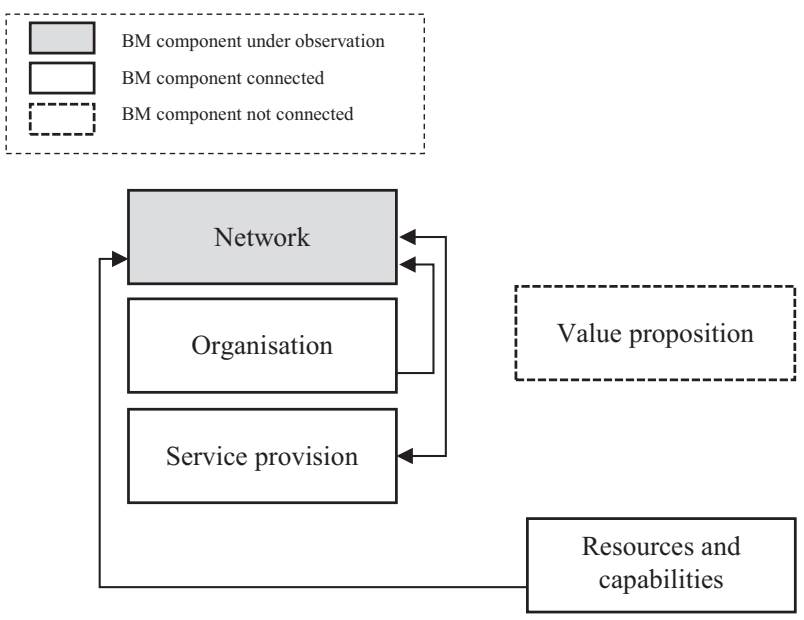

\section{Business models for service centres}

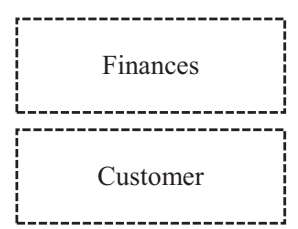

Revenue model

in the service provision, highlighting that successful service centres adopt co-opetitive models, characterised by cooperation rather than competition (Becker et al., 2018). Figure 5 reports the main connections of service provision.

4.3.6 Finances. The reinvested profits constitute the main source of funding used by top performers (Donaldson, 1984). This method of self-financing through reinvested profits is consistent with the nature of top performers that are mainly family businesses, interested more in the long-term survival and growth of the family firm than in short-term financial returns (Caspar et al., 2010). The reinvestment of profits in the company may be considered a point of strength of top performer, as it allows for profitable growth in a context of economic crisis, like the one that has characterised the MHCV industry since 2008. Figure 6 reports the main relationships of this BM component with the others.

4.3.7 Organisation. The organisational structure and mechanisms are adopted by top performers to assure timely and effective communication and information sharing as well as

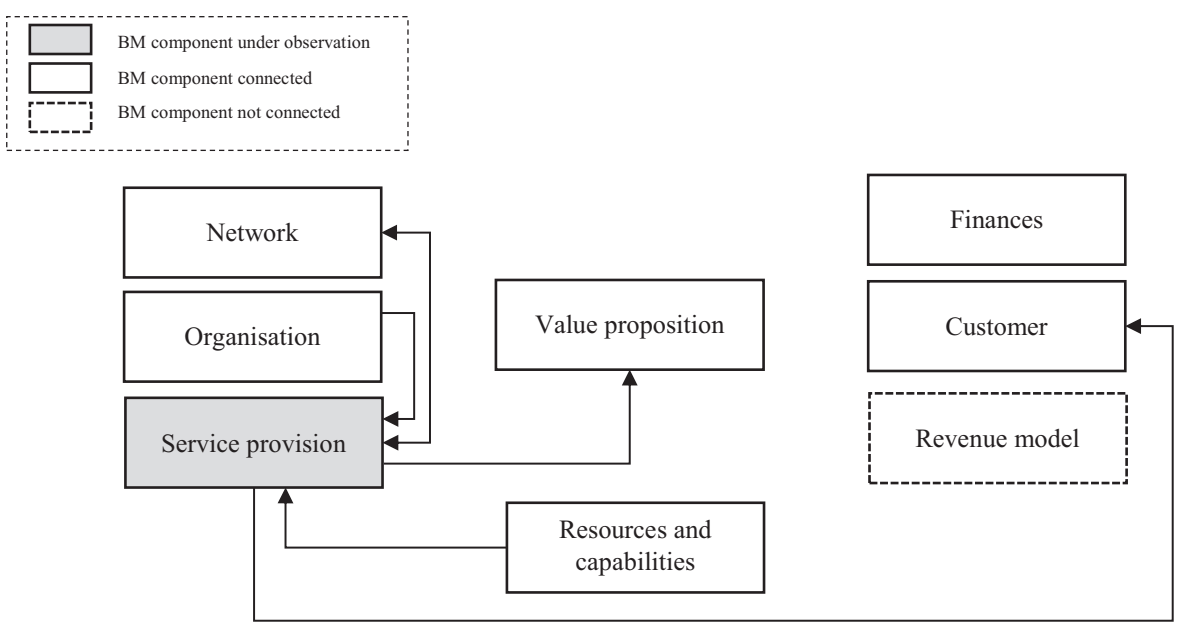

Figure 5.

The relationship between service provision and the other BM components of top performers 


\section{IJPPM 70,5}

1204

Figure 6.

The relationship between finances and the other BM components of top performers
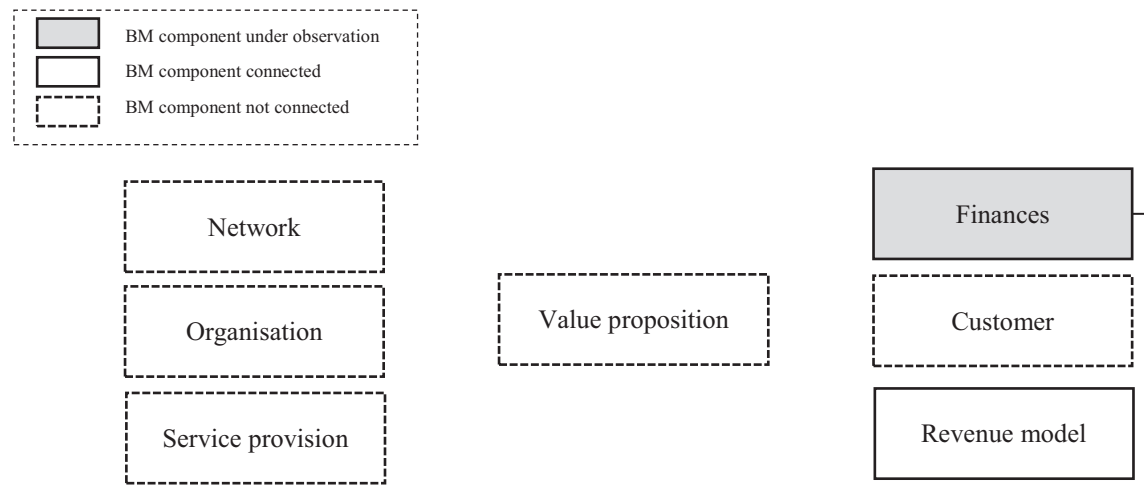

Revenue model

Resources and capabilities

internal and external coordination. With reference to the organisational structure, centralisation is adopted to ensure clarity of roles and responsibilities. Meanwhile, decentralisation - based on lean and flat organisations and cross-functional working groups - promotes the effectiveness of front-office activities and improves customer satisfaction. The decentralisation of key front-office activities can also be delegated to strategic partners in some cases so that each client can be connected on several fronts. Furthermore, these kinds of organisational structures and roles can provide a balance between exploitation (using existing capabilities) and exploration (creating possibilities to stretch capabilities), thus leading to an organisation being ambidextrous, if you will (Duncan, 1976).

Thanks to what has been learnt from the companies that have stimulated managerial skills through the imposition of rigorous monitoring standards, the top performers do not simply draw up a business plan or annual budget and report; they periodically prepare various types of analyses and forecasts for future business plans. Nevertheless, the use of formal mechanisms is coupled with the adoption of informal tools, typical of social and cultural control (Ouchi, 1979). The mix of both informal and formal managerial mechanisms demonstrates the capability of top performers to combine both entrepreneurial and managerial approaches. This attitude is consistent with the characteristics of family businesses and SMEs (Moores and Mula, 2000). As shown in Figure 7, consistently with previous studies (Kowalkowski et al., 2011; He et al., 2015), organisation emerges as a relevant $\mathrm{BM}$ component due to its linkages with most of the other BM components.

4.3.8 Revenue model. The adoption of appropriate market analysis, combined with the customer segmentation and profiling, allows a company to identify different components of customer value consistent with customer needs. This allows for the development of appropriate value-based and tailored pricing policies. The adoption of these new forms of pricing is consistent with the product-service solutions centred on use- and result-oriented perspectives (Pistoni et al., 2018), even if top performers still adopt pricing based on a mark-up for traditional maintenance services and spare parts sales. The relationships between the revenue model and the other BM components are summarised in Figure 8.

4.3.9 Resource and capabilities. Top performers develop with appropriate mechanisms the strategic resources - human and technological - to implement their strategies through both internal and network coordination and control. In particular, human resource management 

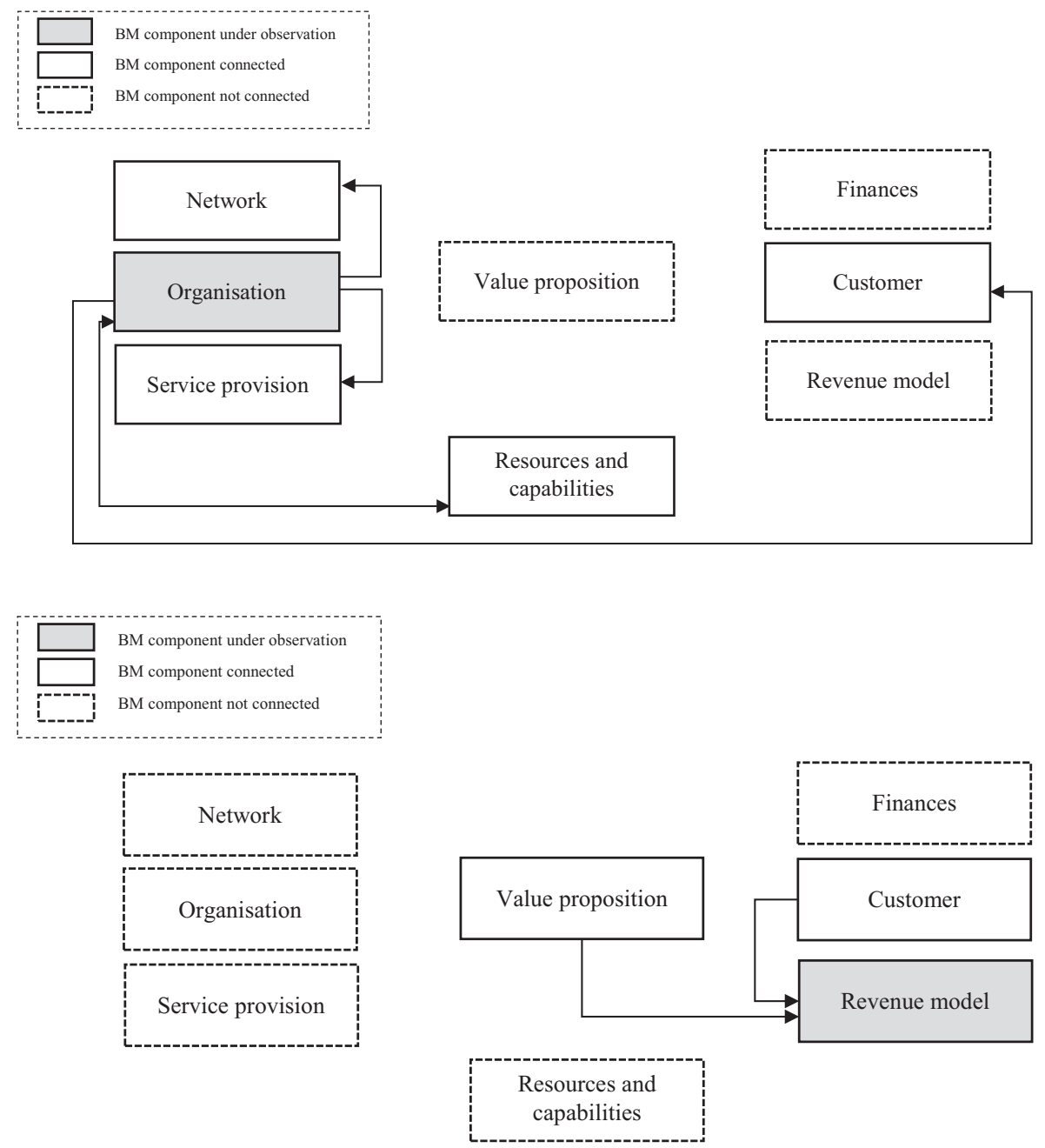

plays a significant role in the acquisition and development of human resources' capabilities, competences and skills. Meanwhile, planning and control mechanisms and financial resources also enhance the acquisition, implementation and adoption of technological resources. This approach is in line with the study by Davies' (2004) suggesting that the adoption of specialised tools to manage and control workers' activities and behaviours enables the development of integrated product-service offerings and, at the same time, employees' commitment and awareness towards service offering a promotion, management and control. Figure 9 reports the main relationships of this BM component with the others.

\section{Conclusions, limitations and future developments}

Often, research on the servisation phenomenon and related BMs focusses on manufacturers and their relationships with customers and partners to understand the logic behind profitability and winning in servitised BMs. Even when the focus has shifted to the network,

\section{Business models for service centres}

1205

Figure 7.

The relationship between organisation and the other BM components of top performers
Figure 8.

The relationships between the revenue model and the other BM components of top performers 


\section{IJPPM 70,5}

\section{6}

Figure 9.

The relationships between resources and capabilities and the other BM components of top performers
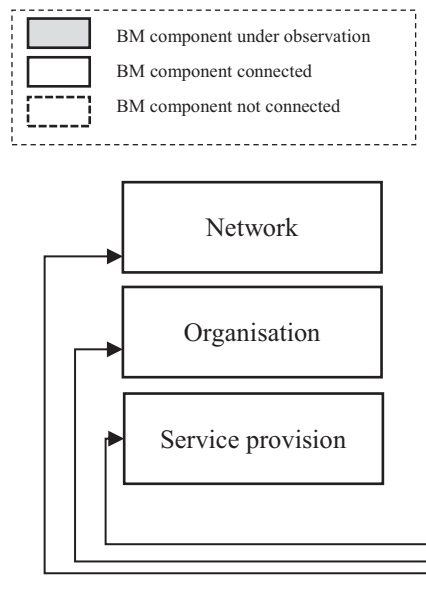

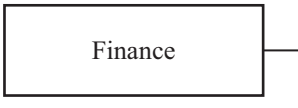

Customer

Revenue Model

Resources and capabilities

the point of view always concerns the perspective of the manufacturer, while the role of service centres has been generally neglected. Instead, focussing on the BMs of these organisations emerges as an extremely important aspect to explore for a comprehensive understanding of servitization. As a result, this paper aimed to analyse the BM configuration of top-performing service centres, leading us to assume that a study on effective BMs of these kinds of organisations could provide some interesting insights to improve knowledge of the dynamics underlying successful servitization strategies.

Using a strategy-structure-performance perspective, our research findings highlight a fit between top performers' strategies and their BMs. Specifically, the study shows that the best service centres adopt a confrontational strategy (Cooper, 1995) based on growth and a mix of cost leadership and differentiation goals. Moreover, they leverage both emergent and deliberate strategies (Mintzberg, 1994). Their BMs present characteristics consistent with the adopted strategy. Indeed, all the BM components are distinguished by a mix of managerial and entrepreneurial approaches as well as formal and informal elements. These features make it possible to combine standardisation and formalisation with flexibility and innovation and highlight a context typical of an ambidextrous organisation - one that can balance exploitation and exploration. All these characteristics allow for the realisation of the confrontation strategy through emergent and deliberate strategies. Furthermore, distinctive characteristics of the service centres' BM components are consistent with each other, having a positive impact on the firm performance.

Our paper has some theoretical implications. First, our research findings support the relevance of contingency theory - particularly of the the strategy-structure-performance paradigm - in the analysis of the role of the BM in successful servitization strategies of service centres. It also allows for the distilling of the multiplicity of BM components provided in the literature into a simple and parsimonious model, while assisting to overcome the extant lack in the literature with regard to the service centres' BM. Third, it confirms the BM configuration proposed by Adrodegari and Saccani (2017), except for the concept of resources that emerged as integrated with capabilities. In particular, we underpin the relevant role of tangible assets and intangible resources such as people's capabilities, competencies and skills (Zott and Amit,2010). These resources are proposed in the literature as key elements for value creation (Abd Aziz et al., 2008).

In addition, our research findings highlight the organisation as an additional component of BM configuration, which is in line with the findings of Kowalkowski et al. (2011) and 
He et al. (2015). These authors addressed the impact of several organisational issues on the provision of services, outlining how an inadequate organisational structure inhibits the success of firms, while an appropriate structure facilitates it (Kindström and Kowalkowski, 2014). Despite that, they stated that it is critical to adopt organisational structures that can balance exploitation and exploration (Duncan, 1976).

Our research also contributes to a deeper understanding of the characteristics of each BM component. In particular, we found that top-performing service centres adopt a confrontational strategy as proposed by Cooper (1995), as well co-opetition models, based on cooperation rather than competition (Becker et al., 2018). Moreover, they develop and offer an integrated and bundled value proposition proposed by value-based pricing schemes, consistent with advanced approaches suggested by the literature on servitization and PSS (Pistoni and Songini, 2018).

Equity, in the way of reinvested profits, represents the main source of funding and plays a relevant role in firm growth and performance (Donaldson, 1984), along with two other main resources: ICT and human capital. Our research findings also confirm that successful BMs are characterised by organisational ambidexterity (Duncan, 1976: March, 1991) and use lean management approaches to cope efficiently and effectively with service provisions (Liker, 2004). Finally, our study highlights the relation amongst all BM components and explains how some characteristics of a firm - such as size and family ownership - may impact on BM configuration.

From a practical point of view, our research findings can give relevant insights to entrepreneurs, managers and practitioners. In particular, research outcomes suggest that successful service centres have to implement a solid financial structure based on equity, formalised and flexible organisational structures and processes, clarity in strategic direction, long-term orientation as well as develop grounded competences, capabilities and skills. Moreover, trustful relationships with main service partners and a comprehensive set of managerial mechanisms have to sustain the achievement of effective and efficient BMs.

Our research findings may help service providers that operate in the downstream channels of different industries to overcome their weaknesses and develop a more consistent and profitable service-based BM. Moreover, we believe that this study can help manufacturers advance effective actions for BM improvement of their partner service centres.

Finally, our research confirms the relationship between the BM characteristics and firm strategy and firm performance - including financial and non-financial results, such as competitiveness and customer satisfaction. However, the question of how each BM component affects the different areas of performance remains.

Our paper presents some limitations typical of qualitative research based on case studies. First, though supported by methodological rigour, the evaluation of research findings presents a certain degree of subjectivity, depending on the researchers' characteristics and school of thought as well as the variables taken into account. For instance, the sample selection followed a definition of "top performer" based on a wide definition of firm performance, which considered different perspectives (Kaplan and Norton, 1992). The selection of sample companies was made following the indications given by a team of experts involved in the research. However, a different definition of what is a top performer is and other people in the group of experts could have led to a different selection of the sample companies. As a consequence, further qualitative research is essential, including a wider panel of experts with different research perspective and taking into account other firms' demographic factors such as firm age, location, ownership strategy and the involvement of the family in the management of the firm.

Moreover, our results have been derived from the analysis of a small sample of service centres. Future quantitative research based on a survey of a wider sample could be useful to
Business models for service centres 
IJPPM

70,5 test and generalise our findings. In addition, as we analysed a specific context in terms of both industry and country, it could be of interest to extend the empirical analysis to different sectors and national contexts, allowing a generalisation of our results. Again, our analysis involved SMEs, and larger companies may show different needs and different components in their BM. Finally, entrepreneurial and managerial practices could be an interesting starting point to deepen the analysis of top performers, as well as extend the discussion concerning characteristi6cs of family-owned firms.

\section{References}

Abd Aziz, S., Fitzsimmons, J.R. and Douglas, E.J. (2008), "Clarifying the business model construct", in Gillin, L. (Ed.), Regional Frontiers of Entrepreneurship Research 2008: Proceedings of the 5th AGSE International Entrepreneurship Research Exchange, Australian Graduate School of Entrepreneurship (AGSE), Swinburne University of Technology, Victoria, Melbourne, pp. $795-813$.

Adler, R.W. (2011), "Performance management and organizational strategy: how to design systems that meet the needs of confrontation strategy firms", The British Accounting Review, Vol. 43 No. 4, pp. 251-263.

Adrodegari, F. and Saccani, N. (2017), "Business models for the service transformation of industrial firms", Service Industries Journal, Vol. 37 No. 1, pp. 57-83.

Adrodegari, F., Saccani, N., Kowalkowski, C. and Vilo, J. (2017), "PSS business model conceptualization and application", Production Planning and Control, Vol. 28 No. 15, pp. 1251-1263.

Al-Debei, M.M. and Avison, D. (2010), "Developing a unified framework of the business model concept”, European Journal of Information Systems, Vol. 19 No. 3, pp. 359-376.

Baines, T., Lightfoot, H., Benedettini, O. and Kay, J. (2009), "The servitization of manufacturing: a review of literature and reflection on future challenges", Journal of Manufacturing Technology Management, Vol. 20 No. 5, pp. 547-567.

Barquet, A.P.B., De Oliveira, M.G., Amigo, C.R., Cunha, V.P. and Rozenfeld, H. (2013), "Employing the business model concept to support the adoption of product-service systems (PSS)", Industrial Marketing Management, Vol. 42 No. 5, pp. 693-704.

Becker, D., Pawelke, M., Schalk, P., Feege, A., Bergmann, U. and Silberg, G. (2018), Kpmg'S Global Automotive Executive Survey 2017, KPMG International.

Bikfalvi, A., Lay, G., Maloca, S. and Waser, B.R. (2013), "Servitization and networking: large-scale survey findings on product-related services", Service Business, Vol. 7 No. 1, pp. 61-82.

Boons, F. and Lüdeke-Freund, F. (2013), "Business models for sustainable innovation: state-of-the-art and steps towards a research agenda", Journal of Cleaner Production, Vol. 45, pp. 9-19.

Casadesus-Masanell, R. and Ricart, J.E. (2010), "From strategy to business models and to tactics", Long Range Planning, Vol. 43, pp. 145-215.

Caspar, C., Dias, A.K. and Elstrodt, H.P. (2010), "The five attributes of enduring family businesses", McKinsey Quarterly, pp. 1-10.

Chandler, A.D. Jr (1962), Strategy and Structure: Chapters in the History of the American Industrial Enterprise, M.I.T. Press, Cambridge, Massachusetts, MA.

Chesbrough, H. (2007), "Business model innovation: it's not just about technology anymore", Strategy and Leadership, Vol. 35 No. 6, pp. 12-17.

Child, J. (1975), "Managerial and organizational factors associated with company performance-Part II. A contingency analysis", Journal of Management Studies, Vol. 12, pp. 12-27.

Cooper, R. (1995), When Lean Enterprises Collde: Competing through Confrontation, Harvard Business Press, Harvard, Boston, Massachusetts, MA. 
Davies, A. (2004), "Moving base into high-value integrated solutions: a value stream approach", Industrial and Corporate Change, Vol. 13 No. 5, pp. 727-756.

Davies, A., Brady, T. and Hobday, M. (2007), "Organizing for solutions: systems seller vs. systems integrator”, Industrial Marketing Management, Vol. 36 No. 2, pp. 183-193.

Dimache, A. and Roche, T. (2013), "A decision methodology to support servitisation of manufacturing", International Journal of Operations and Production Management, Vol. 33 Nos 11-12, pp. 1435-1457.

Donaldson, G. (1984), Managing Corporate Wealth: The Operations of a Comprehensive Financial Goals System, Praeger Publishers, Westport, Connecticut, CT.

Dubois, A. and Gibbert, M. (2010), "From complexity to transparency:managing the interplay between theory, method and empirical phenomena in IMM case studies", Industrial Marketing Management, Vol. 39 No. 1, pp. 129-136.

Duncan, R. (1976), "The ambidextrous organization: designing dual structures for innovation", in Killman, R.H., Pondy, L.R. and Sleven, D. (Eds), The Management of Organization, North Holland, New York, NY, pp. 167-188.

Eisenhardt, K.M. (1989), "Building theories from case study research", Academy of Management Review, Vol. 14 No. 4, pp. 532-550.

Finne, M. and Holmström, J. (2013), "A manufacturer moving upstream: triadic collaboration for service delivery”, Supply Chain Management: An International Journal, Vol. 18 No. 1, pp. 21-33.

Fitzgerald, L., Johnston, R., Brignall, S., Silvestro, R. and Voss, C. (1991), "Performance measurement in service businesses”, International Journal of Service Industry Management, Vol. 7 No. 1, pp. 6-31.

Fitzroy, P.T. and Hulbert, J.M. (2005), Strategic Management: Creating Value in Turbulent Times, John Wiley and Sons Inc, Hoboken, New Jersey, NJ.

Gaiardelli, P. and Songini, L. (2018), Modelli di business servizi e performance nel settore del veicolo pesante, EGEA, Milano, (in Italian).

Gaiardelli, P., Saccani, N. and Songini, L. (2007), "Performance measurement of the after-sales service network: evidence from the automotive industry", Computers in Industry, Vol. 58 No. 7, pp. 698-708.

Gaiardelli, P., Saccani, N. and Songini, L. (2014), "The automotive industry: heading towards servitization in turbulent times", in Lay, G. (Ed.), Servitization in Industry, Springer Books, Cham, pp. 55-72.

Galbraith, J.R. (1977), Organization Design, Addison-Wesley, Reading, Massachusetts, MA.

He, Y., Sun, H., Lai, K.K. and Chen, Y. (2015), "Organizational empowerment and service strategy in manufacturing”, Service Business, Vol. 9 No. 3, pp. 445-462.

Kaplan, R.S. and Norton, D.P. (1992), The Balanced Scorecard: Measures that Drive Performance, Harvard Business School Press, Boston, Massachusetts, MA.

Kaplan, R.S. and Norton, D.P. (2000), "Having trouble with your strategy? then map it", Harvard Business Review, Vol. 78 No. 5, pp. 167-176.

Kaplan, J.M. and Warren, A.C. (2009), Patterns of Entrepreneurship Management, John Wiley and Sons, Hoboken, New Jersey, NJ.

Kindström, D. (2010), "Towards a service-based business model: key aspects for future competitive advantage", European Management Journal, Vol. 28 No. 6, pp. 479-490.

Kindström, D. and Kowalkowski, C. (2014), "Service innovation in product-centric firms: a multidimensional business model perspective", Journal of Business and Industrial Marketing, Vol. 29 No. 2, pp. 96-111.

Kowalkowski, C., Kindström, D. and Brehmer, P.O. (2011), "Managing industrial service offerings in global business markets", Journal of Business and Industrial Marketing, Vol. 26 No. 3, pp. 181-192. 
IJPPM

70,5

Lay, G., Schroeter, M. and Biege, S. (2009), "Service-based business concepts: a typology for businessto-business markets", European Management Journal, Vol. 27 No. 6, pp. 442-455.

Liker, J.K. (2004), The Toyota Way: 14 Management Principles from the World's Greatest Manufacturer, McGraw-Hill Education, New York, NY.

Lockamy, A. (1998), "Quality-focused performance measurement systems: a normative model", International Journal of Operations and Production Management, Vol. 18 No. 8, pp. 740-766.

Luthans, F. and Stewart, T.I. (1977), "A general contingency theory of management”, The Academy of Management Review, Vol. 2 No. 2, pp. 181-195.

Lynch, R.L. and Cross, K.F. (1991), Measure up: The Essential Guide to Measuring Business Performance, Mandarin, London.

Magretta, J. (2002), "Why business models matter”, Harvard Business Review, Vol. 80, pp. 86-92.

March, J.G. (1991), "Exploration and exploitation in organizational learning”, Organization Science, Vol. 2, pp. 71-87.

Martinez, V., Bastl, M., Kingston, J. and Evans, S. (2010), "Challenges in transforming manufacturing organisations into product-service providers", Journal of Manufacturing Technology Management, Vol. 21 No. 4, pp. 449-469.

Miles, R.E. and Snow, C.C. (1978), Organization Structure, Strategy, and Process, McGraw-Hill, New York, NY.

Mintzberg, H. (1994), The Rise and Fall of Strategic Planning, Free Press, New York, NY.

Moores, K. and Mula, J. (2000), "The salience of market, bureaucratic, and clan controls in the management of family firm transitions: some tentative Australian evidence", Family Business Review, Vol. 13 No. 2, pp. 91-106.

Morris, M., Schindehutte, M., Richardson, J. and Allen, J. (2006), "Is the business model a useful strategic concept? Conceptual, theoretical, and empirical insights", Journal of Small Business Strategy, Vol. 17 No. 1, p. 27.

Nadler, D.A. and Tushman, M.L. (1997), Competing by Design, Oxford University Press, Oxford.

Nenonen, S. and Storbacka, K. (2010), "Business model design: conceptualizing networked value co-creation", International Journal of Quality and Service Sciences, Vol. 2 No. 1, pp. 43-59.

Oliva, R. and Kallenberg, R. (2003), "Managing the transition from products to services", International Journal of Service Industry Management, Vol. 14 No. 2, pp. 160-172.

Orellano, M., Neubert, G., Gzara, L. and Le-Dain, M.A. (2017), "Business model configuration for PSS: an explorative study", Procedia CIRP, Vol. 64, pp. 97-102.

Osterwalder, A. and Pigneur, Y. (2010), Business Model Generation: A Handbook for Visionaries, Game Changers, and Challengers, John Wiley and Sons, Hoboken, New Jersey, NJ.

Osterwalder, A., Pigneur, Y. and Tucci, C.L. (2005), "Clarifying business models: origins, present, and future of the concept", Communications of the Association for Information Systems, Vol. 16 No. 1 , p. 1.

Ouchi, W.G. (1979), “A conceptual framework for the design of organizational control mechanisms", Management Science, Vol. 25 No. 9, pp. 833-848.

Pettigrew, A.M. (1990), "Longitudinal field research on change: theory and practice", Organization Science, Vol. 1 No. 3, pp. 267-292.

Pistoni, A. and Songini, L. (2018), Servitization Strategy and Managerial Control, Emerald Group Publishing Limited, Bingley.

Porter, M.E. (1980), Competitive Strategy, Free Press, New York, NY.

Porter, M.E. (2008), "The five competitive forces that shape strategy", Harvard Business Review, Vol. 86 No. 1, pp. 25-40. 
Reim, W., Parida, V. and Örtqvist, D. (2015), "Product-service systems (PSS) business models and tactics-a systematic literature review", Journal of Cleaner Production, Vol. 97, pp. 61-75.

Richter, A., Sadek, T. and Steven, M. (2010), "Flexibility in industrial product-service systems and use-oriented business models", CIRP Journal of Manufacturing Science and Technology, Vol. 3 No. 2, pp. 128-134.

Rishi, S., Gyimesi, K., Burek, C. and Monday, M. (2009), Truck 2020: Transcending Turbulence, Research Report, IBM Institute for Business Value, available at: http://www-935.ibm.com/ services/us/gbs/bus/html/future-of-truck-industry-2020.html.

Saccani, N., Johansson, P. and Perona, M. (2007), "Configuring the after-sales service supply chain: a multiple case study", International Journal of Production Economics, Vol. 110 Nos 1-2, pp. 52-69.

Seddon, P.B., Lewis, G.P., Freeman, P. and Shanks, G. (2004), "The case for viewing business models as abstractions of strategy", Communications of the Association for Information Systems, Vol. 13, pp. 427-442.

Shafer, S.M., Smith, H.J. and Linder, J.C. (2005), "The power of business models”, Business Horizons, Vol. 48 No. 3, pp. 199-207.

Siltaloppi, J. and Vargo, S.L. (2017), "Triads: a review and analytical framework”, Marking Theory, Vol. 17 No. 4, pp. 395-414.

Storbacka, K., Windahl, C., Nenonen, S. and Salonen, A. (2013), "Solution business models: transformation along four continua", Industrial Marketing Management, Vol. 42 No. 5, pp. 705-716.

Strauss, A. and Corbin, J.M. (1990), Basics of Qualitative Research, Sage Publications Inc., Thousand Oaks, California, CA.

Teece, D.J. (2010), "Business models, business strategy and innovation", Long Range Planning, Vol. 43 Nos 2-3, pp. 172-194.

Vargo, S.L. and Lusch, R.F. (2008), "Service-dominant logic: continuing the evolution", Journal of the Academy of Marketing Science, Vol. 36 No. 1, pp. 1-10.

Verstrepen, S., Deschoolmeester, D. and Van den Berg, R.J. (1999), "Servitization in the automotive sector: creating value and competitive advantage through service after sales", in Mertins, K., Krause, O. and Schallock, B. (Eds), Global Production Management, Kluwer Publishers, Boston, Massachusetts, MA, pp. 538-545.

Voss, C., Johnson, M. and Godsell, J. (2016), “Case research”, in Karlsson, C. (Ed.), Research Methods for Operations Management, 2nd ed., Routledge, New York, NY, pp. 165-197.

Westkämper, E., Alting, L. and Arndt, G. (2001), "Life cycle management and assessment: approaches and visions towards sustainable manufacturing", Proceedings of the Institution of Mechanical Engineers, Part B: Journal of Engineering Manufacture, Vol. 215 No. 5, pp. 599-626.

Windahl, C. and Lakemond, N. (2006), "Developing integrated solutions: the importance of relationships within the network", Industrial Marketing Management, Vol. 35 No. 7, pp. 806-818.

Wirtz, B.W., Pistoia, A., Ullrich, S. and Göttel, V. (2016), "Business models: origin, development and future research perspectives", Long Range Planning, Vol. 49 No. 1, pp. 36-54.

Yin, R.K. (2009), Case Study Research: Design and Methods, 4th ed., Sage Publications Inc., Thousand Oaks, California, CA.

Yin, X. and Zajac, E. (2004), "The strategy/governance structure fit relationship: theory and evidence in franchising arrangements", Strategic Management Journal, Vol. 25 No. 4, pp. 365-383.

Zott, C. and Amit, R. (2007), "Business model design and the performance of entrepreneurial firms", Organization Science, Vol. 18 No. 2, pp. 181-199.

Zott, C. and Amit, R. (2008), "The fit between product market strategy and business model: implications for firm performance", Strategic Management Journal, Vol. 29, pp. 1-26.

Zott, C. and Amit, R. (2010), "Business model design: an activity system perspective", Long Range Planning, Vol. 43 No. 2, pp. 216-226.
Business models for service centres 
IJPPM

70,5

1212

\section{About the authors}

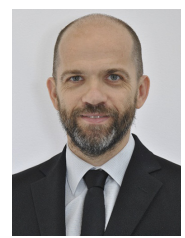

Paolo Gaiardelli is an Associate Professor at Department of Management, Information and Production Engineering of the University of Bergamo. His research subjects mainly focus on Production and Service Management, with a specific interest in Lean Management. Recently his research interests have extended to the exploration of the role of lean management with reference to the main trends in the servitization of manufacturing. In particular, he is involved in studying how the adoption of lean paradigms increases the efficiency and effectiveness of Product Service Systems design, development and management.

Chair Europe of IFIP Working Group 5.7 | Advances in Production Management Systems and coordinator of its Special Interest Group (SIG) in Service Engineering, he is also associate editor Production Planning and Control. Paolo Gaiardelli is the corresponding author and can be contacted at: paolo.gaiardelli@unibg.it

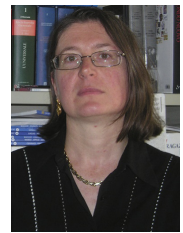

Lucrezia Songini is Full Professor of Managerial Control Systems, Strategic Management in Family Businesses, Cost Management and Performance Management, and Servitization Strategy at Eastern Piedmont University, Novara. She is Rector's delegate for Third Mission and Social Mission. SDA Professor of Accounting and Control at SDA Bocconi School of Management, and Adjunct Professor of Accounting and Control in SMEs at Bocconi University.

National Representative for Italy in the Board of the European Academy of Management (EURAM). She is member of the editorial and review board of Journal of Management and Governance.

For instructions on how to order reprints of this article, please visit our website: www.emeraldgrouppublishing.com/licensing/reprints.htm Or contact us for further details: permissions@emeraldinsight.com 